\title{
Effect of the presence of Actinomycetes in the activated sludge on the quality of the treated wastewater
}

\author{
Elżbieta Bezak-Mazur ${ }^{1}$, Renata Stoińska ${ }^{1, *}$, Jolanta Rajca $^{1}$, and Beata Latasiewicz $^{1}$ \\ ${ }^{1}$ Kielce University of Technology, Faculty of Environmental, Geomatic and Energy Engineering, \\ Department of Water Supply and Sewage Technology, al. Tysiąclecia Państwa Polskiego 7, \\ 25-314 Kielce.
}

\begin{abstract}
The aim of the study was to determine the effect of the Actinomycetes proliferation in the activated sludge on the quality of the treated wastewater and the sewage receiver. The river which is the sewage receiver flows near the wastewater treatment plant. The study was performed on the wastewater (raw and treated) and on the river water samples (collected before and after wastewater discharge). The analysis of the research results, such as the content of total organic carbon (TOC), total phosphorus and oxygen consumption in the examined samples, permit the conclusion that the presence of relatively large population of the Actinomycetes in sewage sludge has a negative impact on the quality of the sewage receiver. Determining the effect of the Actinomycetes in the activated sludge on the wastewater treatment process involved the application of specific analyses, such as Sludge Biotic Index (SBI) and the identification of filamentous bacteria in the activated sludge. The analysis of studies indicates that the presence of the Actinomycetes in the activated sludge adversely affects the efficiency of the wastewater treatment process.
\end{abstract}

\section{Introduction}

One of the most common problems faced by researchers studying sewage treatment plants is poor sludge sedimentation. It results from, i.a., the excessive proliferation of filamentous microorganisms. This phenomenon is defined as "filamentous bulking". Approximately 20 types of filamentous microorganisms are identified in activated sludge [1]. These include microorganisms belonging to the Actinomycetes group, which comprises a number of different bacteria with similar morphology (Nocardia amarae, Nocardia pinensis, Rhodococcus, Gordona, Skermania). These organisms are characterised by true branching and the formation of branched colonies primarily inside or around the sludge flocs. These microorganisms are also distinguished by hydrophobic cell walls, which are responsible for the adverse effect on the process of mechanical wastewater treatment, since they adhere to air bubbles and float together with sludge flocs on the surface of the settling tank thus preventing the sludge sedimentation. Owing to the difficulty in eliminating this

* Corresponding author: rstoinska@tu.kielce.pl 
type of filamentous microorganisms in the activated sludge, it is crucial to recognize the threats to the environment that they may pose.

The aim of the study was to determine the effect of the Actinomycetes proliferation in the activated sludge on the quality of the treated wastewater and the sewage receiver.

\section{Methodology of research}

Determining the effect of the Actinomycetes proliferation in the activated sludge on the quality of the treatment process involved the application of the following analyses:

- The identification of filamentous microorganisms of the Actinomycetes genus in the activated sludge and in the floated sludge flocs in the secondary clarifier. The identification was performed by the method proposed by Eikelboom [2] .

- Microscopic analysis of sludge flocs floating on the wastewater surface in the secondary clarifier. Microscopic analysis of sludge flocs floating on the surface of the wastewater in the secondary settling tank was performed based on the sludge biotic index (SBI) [1]. The microscopic observations were performed using a phase-contrast microscope Delta Optical Evolution 100 coupled to the camera HDCE-X5.

- Phosphorus speciation analysis of the suspended solids contained in the treated wastewater. Phosphorus speciation analysis of the suspended solids was performed by the Golterman method [3]. This method is a sequential extraction scheme where each extraction stage is followed by filtering the sample and its further treatment with a reagent of increasing extraction force [4]. In the first stage the suspended solids sample which was passed through a cellulose filter was subjected to extraction with a solution of $\mathrm{CaNa}_{2}$-EDTA for $4 \mathrm{~h}$. In the second stage the residue formed after the first stage was subjected to extraction with a solution of $\mathrm{Na}_{2}$-EDTA for $18 \mathrm{~h}$. The next stage involved the extraction of the sample with a solution of $\mathrm{H}_{2} \mathrm{SO}_{4}$ for $2 \mathrm{~h}$. The fourth, last step of the sequential extraction lasted for 2 hours and was performed with the application of $\mathrm{NaOH}$ solution. The total phosphorus concentration was determined in the resulting filtrates. The determination of phosphorus was performed by spectrophotometric method using a PERKIN ELMER spectrophotometer UV-VIS Lambda 25.

- The content of total phosphorus in raw and treated wastewater and in the receiver before and after the inflow of the treated wastewater. The river which is the sewage receiver flows near a wastewater treatment plant. The average flow of the river is $0.06 \mathrm{~m}^{3} / \mathrm{s}$ and the nominal capacity of waste water treatment plant is $900 \mathrm{~m}^{3} / \mathrm{d}$. The concentrations of orthophosphates and total phosphorus were determined by spectrophotometry [5] using a PERKIN ELMER spectrophotometer UV-VIS Lambda 25.

- The determination of the chemical oxygen demand (COD) in the sewage and in the wastewater receiver was performed by the permanganate method in accordance with the PN-85/C-04578.02 standard.

- The determination of total organic carbon in the wastewater and in the river water was conducted using the AutoLab analyzer.

\section{Results Analysis}

The analysis started with the macroscopic observation of the activated sludge. For this purpose, the sludge was poured into a graduated cylinder and examined after 30 minutes with regard to its settling properties (Fig. 1). 


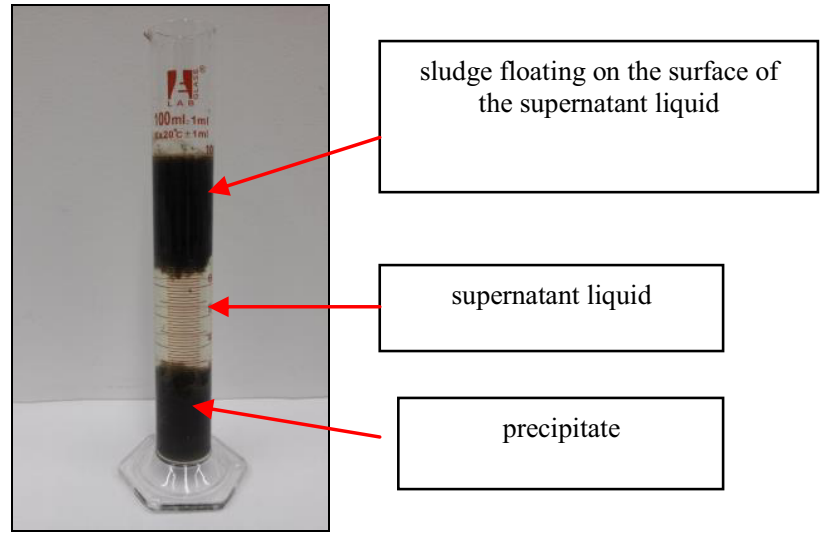

Fig.1. Activated sludge after a 30-minute sedimentation.

It was observed that even after 30 minutes the sludge did not completely settle. The precipitate layer at the bottom of the cylinder amounted to $25 \mathrm{ml}$ and the sludge layer floating on the surface of the supernatant liquid amounted to as much as approximately $30 \mathrm{ml}$. Sludge stratification is a very detrimental phenomenon in the process of mechanical wastewater treatment. The sludge floating on the surface of the supernatant liquid can reach the receiver together with the treated wastewater.

Filamentous bulking caused by an excessive proliferation of filamentous organisms in the sediment is the most common cause of poor sludge sedimentation, therefore, the next step involved the identification of filamentous microorganisms in the activated sludge and in the sludge flocs floating on the surface of the wastewater in the secondary clarifier. The dominant filamentous microorganisms identified in the examined samples belong to the Actinomycetes group. The group of these bacteria stain dark blue when Gram's method is applied and do not change colour in Neisser staining [1]. Figure 2 shows a microscopic picture of the Actinomycetes microorganisms identified in the sludge floating on the surface of the treated wastewater in the secondary settling tank.

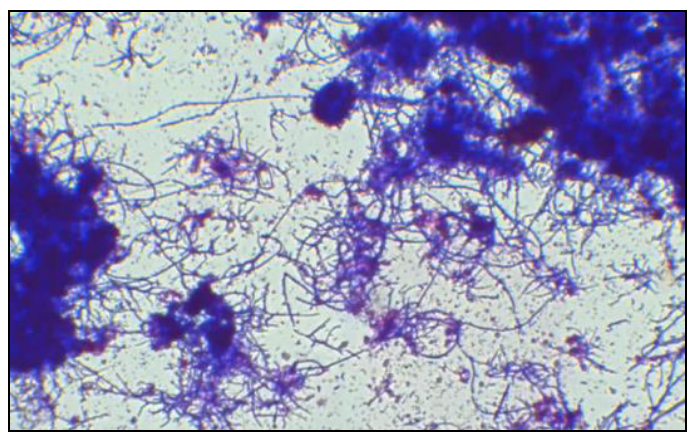

Fig. 2. Actinomycetes microorganisms after the application of Gram staining (400-fold magnification).

Bacteria belonging to the group of Actinomycetes have hydrophobic cell walls, resulting in their adherence to air bubbles and elevation to the surface with sludge flocs. These microorganisms also produce hydrophobic substances. Figure 3 shows a microscopic image of the sludge collected from the surface of the supernatant liquid (Figure 3). The microscopic image shows non-wetting liquid around the sludge floc on the microscope slide. These are probably hydrophobic substances synthesized by the identified filamentous microorganisms. 


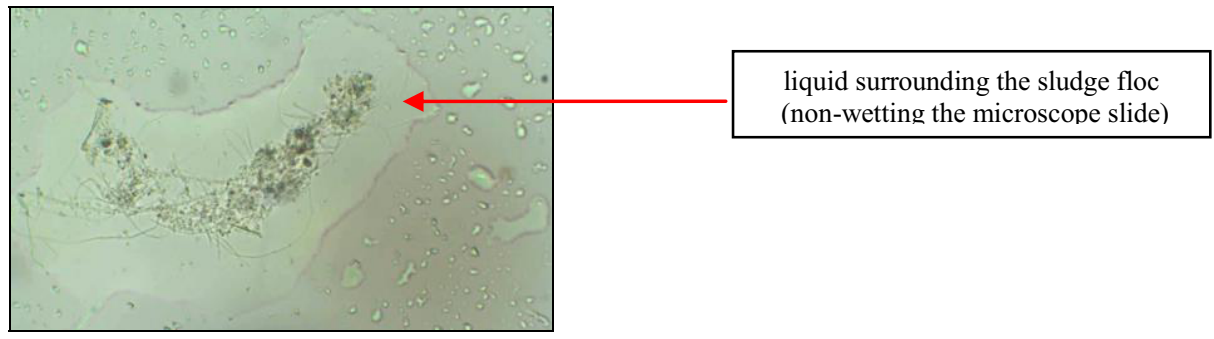

Fig. 3. Microscopic image of a sludge floc floating on the surface of the supernatant liquid.

Therefore the microscopic analysis of the activated sludge and the sludge flocs floating on the surface of the wastewater in the secondary settling tank was performed based on the Sludge Biotic Index [1]. This microscopic analysis allows to define a biological sludge quality on a scale of 0 to 10 and classify the sludge into one of four classes describing the quality of the treatment process. The sludge index value is affected by the density and the kind of the dominant group as well as the biodiversity of the sludge (the number of the protozoa and invertebrates taxa). The microscopic analysis of the sludge showed that the anchored ciliates and testate amoebae constitute the dominant group of the protozoa. They contribute to improving the sludge quality, but their concentration in the sludge does not exceed $1 \times 10^{6}$ microorganisms $/ \mathrm{dm}^{3}$. Moreover, the examined activated sludge does not reveal significant biodiversity. In total there are four identified taxa: testate amoebae, rotifers, anchored ciliates and small swimming flagellates (Fig. 4).

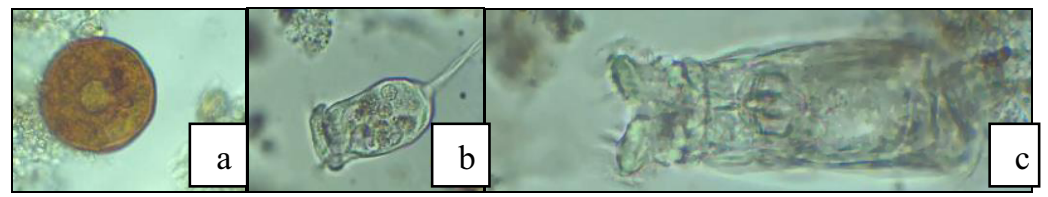

Fig. 4. Taxa of the microorganisms identified in the activated sludge: (a) testate amoeba, (b) anchored ciliate, $(\mathrm{c})$ rotifer.

The value of SBI was estimated as 4 with the use of the table designed for determining the Sludge Biotic Index. It is a low value on the 0-10 scale and the sludge quality is defined as class III. Class III comprises the sludge in which the biological treatment in the aeration tank is insufficient and the sludge is poorly colonized. The analysis of the Biotic Sludge Index was also performed on the sludge composed of flocs floating on the wastewater surface in the secondary settling tank. It appeared to contain even fewer microorganisms, but the analysis of the sludge floating on the wastewater surface that enters the river shows that the lowest possible number of microorganisms would be advisable. On the other hand, protozoa and rotifers provide good filtration of the organic matter and therefore can positively affect portions of the sludge carried away with filamentous bacteria. The transported sludge flocs were dominated by small flagellates. It also contained testate amoeba and rotifers. The Sludge Biotic Index in the examined sample is 1 and thus the sludge is classified as having the lowest, class IV quality, characterized by a very low efficiency of biological wastewater treatment. The microscopic observation of the carried out sludge revealed also the presence of parasite eggs (Figure 5). It was estimated that their concentration is about $12 \times 10^{3}$ eggs $/ \mathrm{dm}^{3}$. 


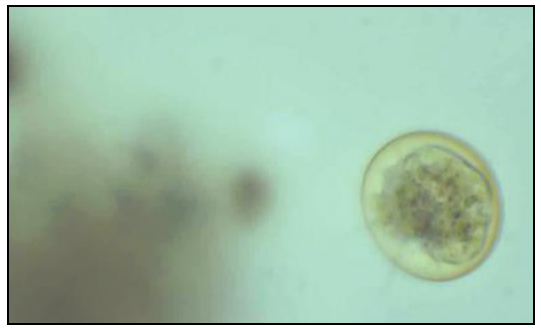

Fig. 5. Fertilized nematode egg.

The picture of nematode egg presented in Fig. 5 was not taken in the course of parasitic egg identification conducted in accordance with standard methodology but during the analysis of the Sludge Biotic Index. Therefore, the egg is not clearly visible in the preparation, and it is difficult to accurately identify its taxonomic affiliation. Nevertheless, the mere presence of potentially parasitic nematode eggs in the sludge discharged into the river is a considerable sanitary threat.

In the secondary clarifier the rising sludge contains not only filamentous microorganisms but also portions of organic matter with a considerable amount of nutrients. The penetration of a high concentration of biogenic elements to the sewage receiver poses a threat to the aquatic environment. The increased concentration of nutrients contributes to water eutrophication. Therefore, the conducted investigation examined the concentration of phosphates, total phosphorus, total organic carbon and chemical oxygen demand in the raw and treated wastewater and in the river before and after the inflow of the treated sewage (Table 1).

Table 1. Measured parameters of sewage and water river.

\begin{tabular}{|c|c|c|c|c|}
\hline & $\begin{array}{c}\text { Raw } \\
\text { sewage }\end{array}$ & $\begin{array}{l}\text { Treated } \\
\text { sewage }\end{array}$ & $\begin{array}{l}\text { River water before } \\
\text { the sewage inflow }\end{array}$ & $\begin{array}{c}\text { River water after } \\
\text { the sewage } \\
\text { inflow }\end{array}$ \\
\hline 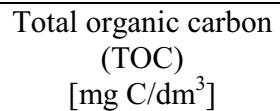 & 85.63 & 41.79 & 21.23 & 36.38 \\
\hline $\begin{array}{c}\text { COD-Mn } \\
{\left[\mathrm{mg} \mathrm{O}_{2} / \mathrm{dm}^{3}\right]}\end{array}$ & 114.1 & 24.2 & 11.0 & 18.8 \\
\hline $\begin{array}{c}\text { Phosphates } \\
{\left[\mathrm{mg} \mathrm{PO}_{4} / \mathrm{dm}^{3}\right]}\end{array}$ & 11.72 & 1.47 & 0.15 & 0.40 \\
\hline $\begin{array}{l}\text { Phosphates } \\
{\left[\mathrm{mg} \mathrm{P}^{2} \mathrm{dm}^{3}\right]}\end{array}$ & 3.82 & 0.48 & 0.05 & 0.13 \\
\hline $\begin{array}{l}\text { Total phosphorus } \\
{\left[\mathrm{mg} \mathrm{P} / \mathrm{dm}^{3}\right]}\end{array}$ & 8.32 & 2.54 & 0.17 & 0.43 \\
\hline
\end{tabular}

The conducted analysis of phosphorus compounds in the river shows that their amount in the receiver was over twice as high after the wastewater discharge as before. The Regulation of the Minister of Environment dated 23 December 2002 on the criteria for designation of water bodies sensitive to pollution by nitrogen compounds from agricultural sources [6] determined the limit values of basic nutrients in water bodies, the exceedance of which indicates the occurrence of eutrophication. According to the provided values, eutrophication in the flowing surface waters occurs when i.a. the total phosphorus content exceeds $0.25 \mathrm{mg} \mathrm{P} / \mathrm{dm}^{3}$. This indicates that when the treated sewage enters the river water the total phosphorus content in the river exceeds the limit value of the eutrophication indicator. Moreover, the analysis of the remaining indicators presented in Table 1 permits the conclusion that the quality of the river water has deteriorated due to the discharge of the treated wastewater. Table 2 presents selected limit values of water quality indicators for surface water quality classes presented in Annex 1 to the Regulation of the Minister of 
Environment dated 11 February 2004 establishing the classification for the presentation of surface waters and groundwater condition, their monitoring and interpretation of results, and the presentation of the state of these waters [7].

Table 2. Selected limit values of water quality indicators for surface water quality classes presented in Annex 1 to the Regulation of the Minister of Environment dated 11 February 2004 [7].

\begin{tabular}{|c|c|c|c|c|c|}
\hline \multirow[t]{2}{*}{ Water quality indicator } & \multicolumn{5}{|c|}{ Limit values in classes I-IV } \\
\hline & I & II & III & IV & $\mathrm{V}$ \\
\hline $\begin{array}{l}\text { COD-Mn } \\
{\left[\mathrm{mgO}_{2} / \mathrm{dm}^{3}\right]}\end{array}$ & 3 & 6 & 12 & 24 & $>24$ \\
\hline 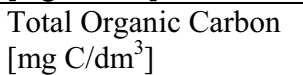 & 5 & 10 & 15 & 20 & $>20$ \\
\hline $\begin{array}{l}\text { Phosphates } \\
{\left[\mathrm{mg} \mathrm{PO}_{4} / \mathrm{dm}^{3}\right]}\end{array}$ & 0.2 & 0.4 & 0.7 & 1.0 & $>1.0$ \\
\hline 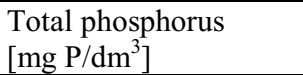 & 0.2 & 0.4 & 0.7 & 1.0 & $>1.0$ \\
\hline
\end{tabular}

Comparing the results of river water examination (Table 1) and the limit values of the water quality in surface water quality classes (Table 2), it can be said that the values of the total organic carbon indicate a decrease from class IV to V class of water quality, whereas the values of phosphates and total phosphorus indicate a decrease from class I to class II of water quality. Merely by analyzing the selected parameters one can notice a deterioration in the surface water quality due to the discharge of the treated wastewater.

The research study of the potential occurrence of eutrophication in the wastewater receiver involves the analysis of the total phosphorus and orthophosphates values. The orthophosphates are determined in the sewage passed through the cellulose filter, whereas total phosphorus is determined in the mineralized and non-filtered wastewater. Subtracting the values of orthophosphates from the total phosphorus value allows the estimation of the phosphorus compounds content in the total suspension. In the case of significant amounts of sludge being elevated in the secondary clarifier the total suspended solids in the treated wastewater will primarily include the particles of the elevated sludge. It was calculated that in the investigated wastewater the value of total suspended solids amounted to $1900 \mathrm{mg} / \mathrm{dm}^{3}$. The value of this parameter is very high considering that in the treated wastewater it usually does not exceed $1000 \mathrm{mg} / \mathrm{dm}^{3}$ [8].

Therefore, in order to determine the amount of phosphorus that can be assimilated by the microorganisms in the river water a phosphorus speciation analysis was performed in the examined suspended solids contained in the treated wastewater. The results of speciation analysis conducted by the Golterman method are shown in Table 3. The phosphorus content in the individual fractions are expressed in $\mathrm{mg} \mathrm{P} / \mathrm{g}$.d.w. In the examined treated wastewater the total suspended solids constituted 1.9 g.d.w $/ \mathrm{dm}^{3}$, and therefore the content of particular phosphorus fractions was also expressed in $\mathrm{mg} \mathrm{P} / \mathrm{dm}^{3}$. According to Golterman the bioavailable phosphorus forms are represented by the fractions Ca-EDTA and Na-EDTA bound to sludge particles [4].

Table 3. Results of the speciation analysis of the suspended solids conducted by the Golterman method in the treated wastewater.

\begin{tabular}{|c|c|c|}
\hline Fraction & $\begin{array}{c}\text { Phosphorus content } \\
{[\mathrm{mg} \mathrm{P} / \mathrm{g} \mathrm{d} . \mathrm{w} .]}\end{array}$ & $\begin{array}{c}\text { Content of particular phosphorus fractions in } \\
1 \mathrm{dm}^{3} \text { of wastewater }\left[\mathrm{mg} \mathrm{P} / \mathrm{dm}^{3}\right]\end{array}$ \\
\hline Ca-EDTA & 0.436 & 0.828 \\
\hline $\mathrm{Na}-\mathrm{EDTA}^{2} \mathrm{SO}_{4}$ & 0.101 & 0.192 \\
\hline $\mathrm{NaOH}$ & 0.174 & 0.331 \\
\hline Total & 0.320 & 0.608 \\
\hline
\end{tabular}


The amount of phosphorus, which is potentially assimilated by the river phytoplankton can be estimated by adding together the content of bioavailable phosphorus forms (fractions Ca-EDTA and Na-EDTA) contained in the sludge (Table 3) and the orthophosphate concentration expressed as elemental phosphorus (Table 1) contained in the treated wastewater:

\section{The concentration of bioavailable phosphorus in treated wastewater $=$ $=C_{P O 4(P)}+C_{C a-E D T A}+C_{N a-E D T A}$}

\section{Calculated concentration of bioavailable phosphorus in treated wastewater $=$} $=0.48 \mathrm{mg} \mathrm{P} / \mathrm{dm}^{3}+0.828 \mathrm{mg} \mathrm{P} / \mathrm{dm}^{3}+0.192 \mathrm{mg} \mathrm{P} / \mathrm{dm}^{3}=1.50 \mathrm{mg} \mathrm{P} / \mathrm{dm}^{3}$

In the case of a large amount of organic matter infiltrating the surface water with the treated sewage, the execution of phosphorus speciation analysis in the separated suspension allows more accurate estimation of the concentration of phosphorus that can be assimilated by the microorganisms and cause eutrophication. The content of total phosphorus in the treated wastewater was $2.54 \mathrm{mg} \mathrm{P} / \mathrm{dm}^{3}$ with the amount of phosphorus that can directly cause eutrophication amounting to $1.50 \mathrm{mg} \mathrm{P} / \mathrm{dm}^{3}$. The amount of bioavailable phosphorus which can directly cause eutrophication makes as much as $64 \%$ of the amount of phosphorus in the treated wastewater (Fig. 6).

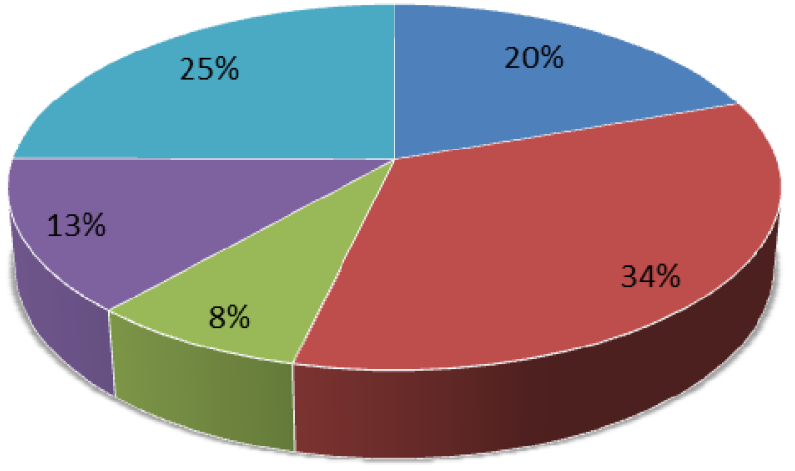

口O4

- Ca-EDTA

- Na-EDTA

- $\mathrm{H} 2 \mathrm{SO} 4$

- $\mathrm{NaOH}$

Total phosphorus $=$ orthophosphates + phosphorus contained in the suspended solids (with the specified speciation forms: Ca-EDTA, Na-EDTA, $\mathrm{H}_{2} \mathrm{SO}_{4}, \mathrm{NaOH}$ )

Fig. 6. Percentage shares of phosphorus forms determined in the treated sewage.

\section{Conclusions}

Based on the conducted research study it can be concluded that the multiplication of the Actinomycetes microorganisms in the activated sludge adversely affects wastewater treatment processes and significantly deteriorates the quality of the treated wastewater, thus endangering the aquatic environment. The results of the speciation analysis of the suspended solids contained in the treated wastewater indicate that the forms which can be assimilated by living organisms causing water eutrophication represent more than half of the phosphorus. Thus it is advisable to perform speciation analysis in the treated sewage containing significant quantities of suspended solids since it allows more accurate assessment of the threat of excessive growth of phytoplankton in the wastewater receiver. 


\section{References}

1. E. Fiałkowska, J. Fyda, A. Pajdak-Stós, K. Wiąckowski, Osad czynny. Biologia i analiza mikroskopowa (Wyd. Seidel-Przywecki, 2009)

2. D.H. Eikelboom, J.J. Buijsenh, Handbuch für die mikroskopische Schlammuntersuchung, (F. Hirthammer Verlag, München, 1983)

3. H L. Golterman, Hydrobiologia, 335 (1996)

4. E. Bezak-Mazur, R. Stoińska, Technologia Wody, 44, 6 (2015)

5. The determination of phosphorus. Spectrophotometric method with ammonium molybdate, BS EN ISO 6878:2004 (2004)

6. Polish Journal of Laws of 2002, item 2093- (The Regulation of the Minister of Environment dated 23 December 2002 on the criteria for designation of water bodies sensitive to pollution by nitrogen compounds from agricultural sources, 2002)

7. Polish Journal of Laws of 2004, item 284-(The Regulation of the Minister of Environment dated 11 February 2004 establishing the classification for the presentation of surface waters and groundwater condition, their monitoring and interpretation of results, and the presentation of the state of these waters, 2004)

8. G. Kaczor, Infrastructure and Ecology of Rural Areas, 3 (2008) 